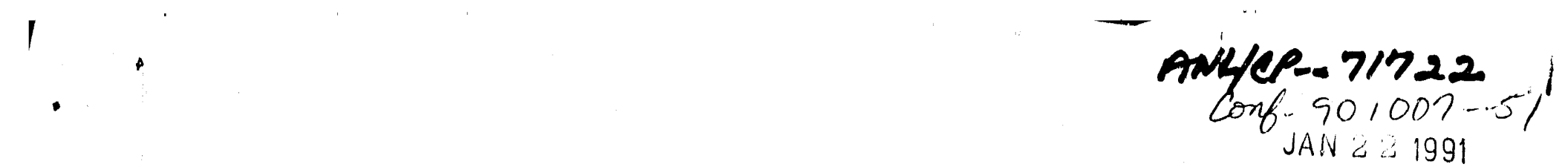

Submitted to the 9th Conference on the Technology of Fusion Energy, Chicago IL Oct. 7-11, 1990

\title{
Li Overlayer Formation, Oxidation and Sputtering Characteristics of Al-Li Alloys and W/Al-Li Composites for Fusion Applications*

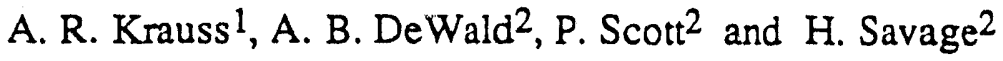
DE91 006529

The next generation of long pulse fusion devices will impose severe requirements on the properties of plasma-facing materials. In devices such as ITER, a divertor design is being considered, using a divertor plate which would be either tungsten or a low- $Z$ material such as graphite or beryllium. Both types of materials present problems. Graphite and beryllium have a relatively high light ion erosion rate, which persists throughout the plasma burn. Tungsten has a much lower sputtering rate for light ion impact, but it is subject to runaway self-sputtering, especially during the first few seconds of the burn. Because of its limited thermal conductivity, it must be used as a relatively thin plate which might be subject to damage during a disruption. Strongly segregating lithium alloys have been proposed as a means of producing a self-sustaining low- $Z$ overlayer which lowers plasma $Z_{\text {eff }}$ and resists self-sputtering. Aluminum-lithium alloys are among the better-characterized lithium-bearing alloys, and it has been demonstrated that lithium segregates strongly in aluminum. However, aluminum has a relatively low melting point, and for low lithium concentrations, the lithium diffusion rate is too slow to replenish lithium at the rate at which it is eroded bythe incoming plasma. It has been suggested previously that the superionic $\beta$ phase Al-Li alloy (48-54 at.\% Li) should have high enough diffusivity to be able to replenish surface lithium, and that incorporation of the $\beta$-phase All $i$ in a composite with tungsten would provide high temperature strength and melt layer stability, along with significantly better thermal conductivity than pure tungsten. Such a composite has been fabricated, as well as a variation containing titanium as a means of ccntrolling oxidation at grain boundaries. The Li overlayer formation, erosion, and replenishment are characterized for the $\beta$-phase LiAl alloy, and W-AlLi and W-Ti-AlIi composites. It is found that if there is no oxide layer to inhibit the Li segregation, Li diffusion is extrentery rapid, and an oxygen-free $\mathrm{Li}$ overlayer is formed which is stable under continuous ion beam sputtering. *Work supported by the U.S. Dept. of Energy Office of Fusion Energy under contract DE. A CO587ER80508 and by BES Materials Sciences under contract W-31-109-ENG-38

1 Argonne National Laboratory, Materials Science and Chemistry Divisions, Argonnc '
2 Corium Industries, Inc. Champaign I 61821

\section{DISCLAIMER}

\begin{abstract}
This report was prepared as an account of work sponsored by an agency of the United States Government. Neither the United States Government nor any agency thereof, $r$ any of their employees, makes any warranty, express or implied, or assumes any legal liablitty or responsibility for the accuracy, completeness, or usefulness of any information, apparatus, product, or process disclosed, or represents that its use would not infringe privately owned rights. Refur. ence herein to any specific commercial product, process, or service by trade name, trademark, manufacturer, or otherwise does not necessarily constitute or imply its endorsement, recommendation, or favoring by the United States Government or any agency thereof. The views and opinions of authors expressed herein do not necessarily state or reflect those of the United States Government or any agency thereof.
\end{abstract}

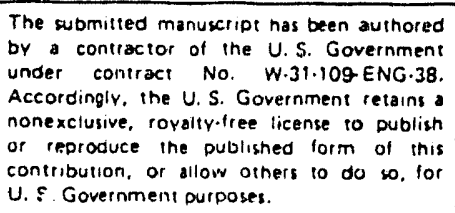




\section{INTRODUCTION}

Thermal and radiation-induced segregation processes in copper-lithium and aluminum-lithium alloys have been shown [1] to result in the formation of coherent lithius overlayers [2] which suppress the sputtering yield of the solvent metal $[3,4]$, in some cases by up to two orders of magnitude for deuteron fluxes up to $5 \times 10^{16} \mathrm{~cm}^{-2} \mathrm{sec}^{-1}$ [5]. These materials have therefore been suggested as plasma-facing materials in magnetic confinement fusion devices [6-8] since they substitute lithium as the principal plasma impurity in place of higher- $Z$ materials which produce greater plasma energy losses as a result of line radiation. Additionally, it has been noted that because of its low ionization potential, lithium tends to sputter with a high fraction of secondary ions, which for $\mathrm{Cu}-\mathrm{Li}$ alloys has been variously reportied to range from 20\% [9] to 90\% [10]. Because of the magnetic and electric field conditions in a magnetic confinement fusion device, the secondary ion component of the sputtered material is trapped at the surface of the plasmafacing structures [7] and does not contribute to the introduction of plasma impurities. Clearly, the observed secondary ion fraction values are very large compared with the range of $10^{-2}-10^{-3}$ for most metals, although the precise value depends strongly on surface conditions. In particular, a $90 \%$ secondary ion fraction would solve the plasma impurity problem whereas a value of $20 \%$ would make only a minor improvement.

For fusion applications, aluminum-lithium alloys have an advantage of low neutron activation and lower average $\mathrm{Z}$ than $\mathrm{Cu}-\mathrm{Li}$ alloys. However, high electrical conductivity and low melting point make aluminum-lithium alloys unsuitable for applications in which they might be exposed to a plasma disruption. Additionally, because aluminum has a lower work function than copper, it is to be expected that lithium sputtered from an aluminum surface would have a lower secondary ion fraction than lithium sputtered from a copper surface. It has been pointed out however, [11], that a composite material consisting of an $\mathrm{Al}-\mathrm{Li}$ alloy imbedded in a structurally contiguous matrix of a refractory metal such as tungsten would have both high thermal conductivity and good high temperature strength and melt layer stability. Materials such as copper infiltrated into tungsten are for example, used for high current electrical contacts where thermal and electrical conductivity must be high, but the contact material must resist melting and pitting due to the arc which forms when contact is broken. In cases of extremely high power density, the lower melting component "wicks" to the surface where it forms a molten layer which may be subject to melt layer instability. However the thickness of this layer is limited to the meniscus height, and disruption damage in a fusion device would be confined to a thin layer above the original surface. In addition, tungsten has a work function which is somewhat higher than copper, and lithium sputtered from ine tungsten portions of the surface would be expected to have a correspondingly higher secondary ion fraction. Calculations of the total sputtering yield from such a composite material $[11,12]$ indicate that $\mathrm{W}$-Alli is much more resistant to runaway self-sputtering than most other materials currently being considered for plasma-facing components.

For the Al-Li system, it has been predicted $[2,3,13]$ that thermodynamic equilibrium corresponds to a surface which is entrely covered by lithium. This prediction has been experimentally verified for $\alpha$ phase $\mathrm{Al}-\mathrm{Li}$ alloys, containing up to $10 \mathrm{at} \% \mathrm{Li}$ $[1,14]$. Measurements of the sputtering characteristics of these segregated layers show that the aluminum erosion rate is reduced to $25-50 \%$ [14] of the value for bare aluminum, in accord with earlier calculations [15]. Li depth profiles [14] of the $\alpha$ phase alloy show that under the influence of continued particle bombardment, radiation-induced segregation effects are not significant, and that the replenishment of the Li overlayer is largely 
determined by diffusion from the immediate subsurface to the surface, accompanied by a depletion of the lithium subsurface concentration until surface replenishment at steady state is limited by Li transport through the depletion region, typically several $\mu \mathrm{m}$ thick [16]. Experimentally, this condition occurs quickly for the $\alpha$ phase alloy $[1,14]$ and, since the melting point is relatively low, it is not possible to significantly increase the thickness of the depletion layer and therefore the available $\mathrm{Li}$ by increasing the temperature.

For the $\beta$ phase alloy (48-54 at.\% Li), the Li diffusion coefficient (Fig. 1), is many orders of magnitude larger than in the $\alpha$ phase [17], resulting in a corresponding increase in the amount of available Li before the diffusion process is inhibited by transport through the depletion layer. Depending on the temperature, the available Li corresponds to the lithium contained in a layer several $\mathrm{mm}$ or even several $\mathrm{cm}$ thick. For many fusionrelevant structures, the $\mathrm{Li}$ depletion lifetime of a plasma-facing component would be determined by the requirement that the bulk concentration remain above 48 at. $\%$, rather than by limited diffusivity in the depletion layer. It should especially be noted that even for long pulse machines, the period between pulses acts as a "healing period" in which the temperature is still sufficiently high to permit redistribution of concentration gradients resulting from loss of lithium at the surface [18]. Because of the high diffusion coefficient, it should be possible to maintain a lithium overlayer at a lower temperature than the value of approximately $450^{\circ} \mathrm{C}$ which is required for high flux sputtering of copper-lithium alloys $[5,19]$. This paper presents the results of a study by Auger spectroscopy on the lithium overlayer formation in $\beta$ phase $\mathrm{Al}-\mathrm{Li}$ alloys and $\mathrm{W}-\mathrm{Al}-\mathrm{Li}$ and $\mathrm{W}-\mathrm{Al}-\mathrm{Li}-\mathrm{Ti}$ composites. One of the key points addressed by this study is the determination of the extent to which the lithium forms a contiguous overlayer on the inhomogeneous tungstenaluminum surface.

One issue which has surfaced with regard to copper-lithium alloys concerns the lithium diffusion rate as a function of temperature, and the effect of oxygen on the rate at which lithium which is sputtered from the surface can be replenished by diffusion from the bulk. It is to be expected, based on thermodynamic considerations, that adsorbed oxygen will promote the formation of a lithium overlayer, but it also appears that the formation of lithium oxide at the surface and at grain boundaries suppresses the lithium diffusion rate, and therefore the rate at which lithium at the surface can be replenished. $\mathrm{A} \mathrm{Cu}-16 \% \mathrm{Li}$ sample which initially was able to replenish the lithium surface layer at a rate of 5-10 monolayers/second during continuous sputtering for more than 20 hours at $450^{\circ} \mathrm{C}$ [5] was re-examined several years after the initial experiments, and it was concluded [9] that the lithium diffusion rate was much lower than the previously observed values. Analysis of the near-surface oxygen concentration by nuclear reaction analysis revealed that the lithium content in the first $10 \mu \mathrm{m}$ had increased tc $24 \%$ and the first $0.2 \mu \mathrm{m}$ had an oxygen content of up to $10^{22} \mathrm{~cm}^{-3}$.

Since aluminum has a higher oxygen affinity than copper, there is a possibility that oxidation effects will be more serious than in the copper-lithium system. It has been reported $[20,21]$ that for the $\mathrm{Cu}-\mathrm{Li}$ system, the addition of beryllium acts as a sub-surface getter, permitting the formation of a nearly oxygen-free lithium surface. In this context, we have produced $\mathrm{W}$-Ti- $(\beta$ AlLi) composites to determine if it is similarly possible to produce oxygen-free lithium overlayers on tungsten-aluminum composite materials. 


\section{THEORY}

At thermal equilibrimm, the surface composition is given by the Gibbsian condition of minimum surface free energy at temperature $\mathrm{T}$ :

$$
\mathrm{C}_{1 \mathrm{a}} / \mathrm{C}_{1 \mathrm{~b}}=\left(\mathrm{C}_{\mathrm{a}} / \mathrm{C}_{\mathrm{b}}\right) \exp \left(-\Delta \mathrm{H}_{\mathrm{s}} / \mathrm{kT}\right)
$$

where $k$ is Boltzmann's constant, $C_{1 a}, C_{1 b}$ are the concentration of species a and $b$ in the first atomic layer, $\mathrm{C}_{\mathrm{a}}, \mathrm{C}_{\mathrm{b}}$ are bulk concentrations of $\mathrm{a}$ and $\underline{b}$, and $\Delta \mathrm{H}_{\mathrm{s}}$ is the Gibbs free energy of the surface. Steady state under a beam of incident energetic ions is reached when diffusion to the surface is limited by subsurface solute depletion. The flux of species a to the surface is given by:

$$
\Omega_{\mathrm{a}} \mathrm{J}_{\mathrm{a}}=-\mathrm{D}_{\mathrm{a}} \nabla \mathrm{C}_{\mathrm{a}}
$$

where $\Omega_{a}$ is the atomic volume of species $\underline{a}, J_{a}$ is the flux of species a to the surface, $D_{a}$ is the diffusion coefficient for solute species $\underline{a}$ in solvent $\underline{b}$, and $\nabla C_{a}$ is the concentration gradient of species a. At steady state, this flux is equal to Nv, the rate at which solute atoms are removed by sputtering. If it is assumed that $C_{a}(x)$ in the near-surface regionis given by an expression of the form

$$
C_{a}(x)=C_{a} \exp (-x / \lambda)
$$

then the solute depletion profile can be specified in terms of a characteristic length $\lambda$ which is given by:

$$
\lambda=\mathrm{D}_{\mathrm{a}} / \mathrm{v} .
$$

Writing $D_{a}$ in the usual form,

$$
\mathrm{D}_{\mathrm{a}}=\mathrm{D}_{0} \exp \left(-\mathrm{E}_{\mathrm{a}} / \mathrm{kT}\right),
$$

$D_{0}$ and $E_{a}$ can be evaluated from the literature for $\alpha$ and $\beta$-LiAL, and CuLi alloys [14,17] as a function of temperature. At $300^{\circ} \mathrm{C}, \mathrm{D}_{\mathrm{a}}$ for $\beta$-LiAL is $10^{5}$ greater than for $\alpha$-LiAl or CuLi alloys, as shown in Fig. 1. The resulting lithium fluxes for $\alpha$-LiAl and $\beta$-LiAl given by Eq. 2 are shown in Fig. $2 a$ and $2 b$. In both cases, the dashed line represents a constant surface removal rate of $10^{15}$ atoms $/ \mathrm{cm}^{2}$-sec, approximately one monolayer/second.

The lithium replenishment rate for $\alpha$-LiAl (Fig. 2a) is strongly temperature-dependent, and for temperatures of $300^{\circ} \mathrm{C}$ or less, the replenishment rate drops below the removal rate almost immediately and it is found that the lithium overlayer can not be sustained during sputtering, in accord with previous experimental results [3,4]. For $\beta$-LiAl (Fig. 2b), the lithium replenishment rate has a much weaker temperature dependence, and is much higher than for the $\alpha$-phase material. For a constant Li removal rate of $10^{15} \mathrm{atom} / / \mathrm{cm}^{2}-\mathrm{sec}$, it is predicted that the lithium overlayer can be sustained for approximately $10^{6}$ seconds. For present plasma devices and projected "long pulse" magnetic confinement fusio:a devices, the pulse length is much shorter than this. As discussed elsewhere [18], continued high temperature between pulses acts to level the lithium concentration gradient, providing a "healing" effect which increases the usable lithium inventory. 


\section{EXPERIMENTAL}

The W-(LiAl) and the W-(LiAl)-Ti samples were processed via the cold compaction of a powder mixtures consisting of 80 at. $\% \mathrm{~W}$ and 20 at.\% beta-phase LiAl powdeïs, and 80 at.\% W, 10 at.\% beta-phase $\mathrm{LiAl}$, and 10 at.\% Ti, respectively. Subsequent HIP processing under a pressure of $25 \mathrm{ksi}$ at a temperature in excess of $1000{ }^{\circ} \mathrm{C}$ was used to solidify the W-based composites.

A Physical Electronics model 595 microprobe was used for the scanning Auger electron microscopy analysis of all of the lithium metal-bearing alloys and composites. A pressure of less than $4 \times 10^{-8}$ torr was maintained during the Auger analyses of the samples. The temperature of the sample was controlled and monitored by using a type $\mathrm{K}$ thermocouple that measures the temperature of the tantalum backing plate on which the sample is mounted. The electron beam current impinging upon the sample surface was held constant at $40 \mathrm{nA}$ for the W-(L,iAl) sample. A constant argon ion flux of approximately $22 \mu \mathrm{A} / \mathrm{cm}^{2}$ (as measured with a Faraday cup) at energies of $3.0 \mathrm{keV}$ was used for the sputtering analysis of the samples.

\section{RESULTS \& DISCUSSION}

\section{$\beta$-LiAl}

B-LiAl alloy, supplied by Eagle-Pitcher, was used in the as-supplied state, and the surface was found to consist principally of oxygen, lithium $\left(\operatorname{as~} \mathrm{Li}_{2} \mathrm{O}\right)$ and some carbon, as shown in Fig. 3a. The aluminum, if visible at all, was seen only in the high energy $(* * ?$ ? $\mathrm{eV}) \mathrm{LMM}$ peak, indicating that the $\mathrm{Li} 2 \mathrm{O}$ surface layers was everywhere at least several monolayers thick.

Room temperature sputtering results in the appearance of the high energy aluminum line, and the $67 \mathrm{eV}$ KLL peak for metallic aluminum as well as the $53 \mathrm{eV}$ peak commonly ascribed to $\mathrm{Al}_{2} \mathrm{O}_{3}$. Unfortunately, the metallic lithium line lies at the same energy [21] and is not immediately distinguishable from $\mathrm{Al}_{2} \mathrm{O}_{3}$. The $41 \mathrm{eV}$ peak normally ascribed to lithium metal is actually $\mathrm{Li}_{2} \mathrm{O}$. By quantifying the amount of oxygen associated with the $\mathrm{Li}_{2} \mathrm{O}$, and ascribing the balance of the oxygen to $\mathrm{Al}_{2} \mathrm{O}_{3}$, it is possible to identify excess intensity in the $53 \mathrm{eV}$ peak as lithium metal.

Continued sputtering at elevated temperature $\left(260^{\circ} \mathrm{C}\right)$ primarily results in the loss of oxygen, the growth of the $67 \mathrm{eV} \mathrm{Al}$ (metal) and $53 \mathrm{eV}\left(\mathrm{Al}_{2} \mathrm{O}_{3}\right.$ and $\mathrm{Li} \mathrm{(metal))} \mathrm{lines,} \mathrm{along}$ with a significant decrease in the $41 \mathrm{eV} \mathrm{Li} 2 \mathrm{O}$ intensity. Eventually (Fig. 3b), the oxygen signal nearly disappears, along with the $41 \mathrm{eV} \mathrm{Li} 2 \mathrm{O}$ line, and the $67 \mathrm{eV} \mathrm{Al}$ (metal) and the $53 \mathrm{eV}$ lines increase. Since there is so little oxygen, the intensity of the $53 \mathrm{eV}$ line may be ascribed entirely to metallic $\mathrm{Li}$. With this assignment, the surface composition is found to be approximately $68 \%$ lithium and $32 \% \mathrm{Al}$. These values appear to be stable indefinitely and are close to the preferential sputtering limit. Application of a negative bias voltage to the sample as a means of retaining the secondary ions did not result in a clear enhancement of the $\mathrm{Li} / \mathrm{Al}$ Auger peak height ratio. Turning the ion beam off resulted in rapid recontamination of the surface by oxygen 


\section{$\mathrm{W}_{80}-(\mathrm{AlLi})_{20}$}

After sputter-cleaning at room temperature, the surface of the sample consisted primarily of tungsten oxide, plus some residual carbon. Upon heating to $275^{\circ} \mathrm{C}$, it was found that the surface had become almost entirely covered by lithium oxide, as shown in Fig. 4a. After sputtering for 20 minutes by a $3 \mathrm{keV} \mathrm{Ar}+$ ion beam at a current density of 22 $\mathrm{uA} / \mathrm{cm}^{2}$, the lithium oxide layer had thinned, and the $53 \mathrm{eV} \mathrm{Li}$ (metal)/ $\mathrm{Al}_{2} \mathrm{O}_{3}$ signal had decreased while the $169 \mathrm{eV} \mathrm{W}$ (KLL) peak and the $67 \mathrm{eV} \mathrm{Al} \mathrm{(KLL)} \mathrm{peak} \mathrm{increased,as}$ shown in Fig. 4b. The oxygen signal intensity indicates that the $53 \mathrm{eV}$ line is primarily $\mathrm{Al}_{2} \mathrm{O}_{3}$.

Upon moving the analysis area to another spot which had not been sputtered, the Auger survey spectrum was found to be similar to that of Fig. 4a. Application of a -22 volt bias to the sample shifted all Auger peaks by the same energy and reduced the signal intensity for all lines, although the intensity of lithium oxide peak increased relative to the $510 \mathrm{eV} \mathrm{O}$ (KLL) line by about $75 \%$. An enhancement of $60 \%$ and $30 \%$ for the lithium metal and tungsten peaks, respectively was observed. By applying the (1/1.75) factor to the lithium oxide peak, the oxygen peak intensity is found consistent with the measured amount of lithium oxide. Sputtering this area for 20 minutes at the previous ion current density resulted in a decrease in the $67 \mathrm{eV} \mathrm{Al}$ (metal) concentration, and a further decrease in the $\mathrm{O}(\mathrm{KLL})$ line. At the same time the $53 \mathrm{eV}$ line, corresponding in this case to lithium (metal) increased in intensity. The survey spectrum, shifted $22 \mathrm{eV}$ to correct the kinetic energy for the sample bias voltage, is shown in Fig, 4c.

The progression of the above described sequence is shown in more detail in Fig. 5. The measured lithium concentration remains nearly constant at about 70 atomic percent of the surface region to a depth determined by the attenuation length of the Auger electrons (typically 3-10 A). As sputtering proceeds, the oxygen concentration decreases from approximately 20 at.\% to 10 at. \%, and the lithium is largely converted from $\mathrm{Li}_{2} \mathrm{O}$ to lithium metal. The total aluminum signal decreases from approximately 10 at.\% to 5 at.\%, and the tungsten remains approximately constant at a value of $5 \%$.

Comparing this result with the previous data for $\beta$-Alli and the unbiased W-AlLi composite, it is clear that the lithium covers the entire composite surface with a uniform overlayer, and that the application of a negative bias voltage to the sample acts to suppress loss of lithium during sputtering if a significant portion of the substrate material is tungsten, rather than Al-Li alloy.

$\mathrm{W}_{80}(\mathrm{AlLi})_{10} \mathrm{Ti}_{10}$

After a brief room temperature sputter cleaning, the W-(LiAl)-Ti composite surface consists primarily of tungsten, titanium, oxygen, and carbon, largely as a bulk impurity from the HIP process. When the sample temperature is increased to $275^{\circ} \mathrm{C}$, a change in surface composition is observed such that the surface consists of lithium oxide and small amounts of tungsten and carbon, and the Auger spectrum is similar to that shown in Fig. 4 for the $\mathrm{W}_{80}(\text { All })_{20}$ composite.

Ás a result of sputtering by $3 \mathrm{keV} \mathrm{Ar}{ }^{+}$at a current density of $22 \mathrm{uA} / \mathrm{cm}^{2}$ at a ternperature of $275^{\circ} \mathrm{C}$, the surface composition changed dramatically, as shown in Fig. 6. Numbers enclosed in braces (] represent total sputtering time. The initial effect of sputtering was to decrease the W (169 eV) Auger signal and increase both the oxygen and lithium concentration (as $\mathrm{Li}_{2} \mathrm{O}$ ). With continued sputtering, toth the oxygen and $\mathrm{Li}_{2} \mathrm{O}$ 
levels fell precipitously and $\mathrm{Li}$ (metal) became the principal surface species. After sputtering for 20 minutes, the surface composition was 80 at. $\% \mathrm{Li}, 10$ at. $\% \mathrm{O}, 8$ at. $\% \mathrm{~W}$, and 2 at.\% Al. The ion gun was then turned off and the total (oxide + metal) surface lithium concentration continued to increase until only about 2 at.\% Ti remained and oxygen and aluminum were completely gone. The Auger spectrum corresponding to this state is shown in Fig. 7. Since the surface is already nearly pure metallic lithium, it was not expected that there would be any significant change in the surface composition when a negative bias voltage was applied to the sample, and none was observed.

\section{SUMMARY}

Formation of an intact lithium overlayer as a result of Gibbsian segregation is observed to occur at lower temperatures in both $\alpha$ and $\beta$-phase AlLi alloys than in the CuLi alloy. Although the diffusion coefficient of lithium is many orders of magnitude higher in the $\beta$-phase AlLi than in the $\alpha$-phase or the CuLi alloy systems, it does not appear possible to maintain a pure lithium overlayer during prolonged high temperature sputtering. The steady state surface composition during sputtering at $260^{\circ} \mathrm{C}$ by $3 \mathrm{keV}$ Art at a current density of $22 \mu \mathrm{A} / \mathrm{cm}^{2}$ consisted of nearly oxygen-free lithium and aluminum in a ratio $\mathrm{Li}: \mathrm{Al}=2: 1$ although the bulk composition was close to $1: 1$. This surface promptly became oxygen contaminated when sputtering stopped. Application of a negative bias voltage to the sample had no effect on the surface composition, indicating a low lithium secondary ion fraction as expected given the low work function of the aluminum substrate.

When no bias voltage was applied, results for the W- $\beta$ Alli alloy sputtered at $275^{\circ} \mathrm{C}$ were qualitatively similar to those for the pure $\beta$-AlLi. Although the lithium remained as a major surface component, it was present entirely as $\mathrm{Li}_{2} \mathrm{O}$. However, the application of a 22 volt bias during sputtering was accompanied by a decrease in the oxygen, aluminum and tungsten concentration at the surface, while the dominant lithium was converted largely to metallic lithium. Although lithium comprised only 10 at.\% of the bulk composition, it made up approximately 70 at.\% of the surface composition. The tungsten, which made up $80 \%$ of the bulk, was found to account for only $5 \%$ of the atoms in the near-surface region. The lithium, which covered the tungsten and aluminum in a thin layer was sputtered with a high ion fraction, presumably associated with the large tungsten surface area, and was consequently trapped at the surface by the bias voltage. It is therefore to be expected that similar changes in surface composition and consequent reduction in high- $Z$ sputtering would occur for plasma-facing components made of this material.

Sputtering the W-Ti-Alli composite at $275^{\circ} \mathrm{C}$ results in the loss of surface oxygen and the formation of a coherent lithium overlayer which covers both tungsten and aluminum portions of the surface. Once the majority of the initial lithium oxide layer has been removed by sputtering, continued heating (without sputtering) at $275^{\circ} \mathrm{C}$ results in continued loss of oxygen at the surface, presumably as a result of gettering by titanium at the grain boundaries, until a surface consisting of nearly pure metallic lithium is formed. It is difficult to say what the sputtering-induced lithium loss rate from such a surface would be since the Li replenishment rate by diffusion from the bulk seems to be so high that a $\mathrm{Li}$ covered surface is maintained even in the absence of a bias voltage at the sample during sputtering. 


\section{FIGURE CAPTIONS}

Fig. 1. Calculated Li diffusion coefficient in CuLi and $\alpha$ and $\beta$-phase AlLi ailoys as a function of temperature.

Fig. 2 Plot of the calculated time-dependent lithium flux to the surface (solid lines) for (a) $\alpha$ and (b) $\beta$-phase Alli alloys for four different temperatures, and (dashed lines) lithium removal rate for a fixed loss rate of $1 \times 10^{15} \mathrm{Li}$ atoms $/ \mathrm{cm}^{2}-\mathrm{sec}$, corresponding to an incident flux of approximately $10^{17} 100 \mathrm{eV}$ deuterons $/ \mathrm{cm}^{2}$-sec. The material is considered to be depleted when the $\mathrm{Li}$ removal rate exceeds the replenishment rate. This condition occurs almost immediately for the $\alpha$-phase AlLi alloy, but requires approximately $10^{6}$ seconds for the $\beta$-phase alloy.

Fig. 3 Auger spectra of $\beta$-Alli (a) at room temperature after a light sputter-cleaning. The largest lines correspond to oxygen $\mathrm{KLL}(510 \mathrm{eV})$ and to lithium oxide (41 eV). After 221 minutes of sputtering at $260^{\circ} \mathrm{C}$ (b), the oxygen and Lithium oxide peaks are nearly gone, and the surface consists of metallic $\mathrm{Li}(53 \mathrm{eV})$ and $\mathrm{Al}(67 \mathrm{eV})$.

Fig. 4 Auger spectra of a $\mathrm{W}_{80}-(\mathrm{Alli}){ }_{20}$ composite at $275^{\circ} \mathrm{C}$ (a) after no sputtering, (b) after sputtering for 20 minutes, and (c) after sputtering for 20 minutes with a -22 volt bias applied to the sample.

Fig. 5 Surface composition of a $W_{80}$-(AlLi) 20 composite as a function of sputtering time at $275^{\circ} \mathrm{C}$, with a -22 volt bias applied to the sample.

Fig. 6 Surface composition of a $\mathrm{W}_{80}-\mathrm{Ti}_{10}-(\mathrm{AlLi})_{10}$ composite as a function of sputtering time at $275^{\circ} \mathrm{C}$.

Fig. 7 Auger spectra of a $\mathrm{W}_{80}-(\mathrm{AlLi})_{20}$ composite at $275^{\circ} \mathrm{C}$ (a) after a light sputtering, and (b) after sputtering for 20 minutes. The oxygen has disappeared, and the lithium line has shifted from $\mathrm{Li}_{2} \mathrm{O}$ to $\mathrm{Li}$ (metal). 


\section{REFERENCES}

1. D. M. Gruen, A.R. Krauss, S. Susman, M. Venugopalan and M. Ron, J. Vac. Sci.Technol A.1 (1983) 924

2. A. R. Krauss, D. M. Gruen and A. B. DeWald, proc. 9th Symp. on Engineering Problems in Fusion Research, Chicago Il (1981) p. 1633, IEEE Pub. 81CH1715-2 NPS

3. A. R. Krauss and D. M. Gruen, J. Nucl. Mater. 103 \& 104 (1981) 239

4. A. R. Krauss, D. M. Gruen and A. B. DeWald, J. Nucl. Mater. 121 (1984) 398

5. J. Bohdansky and J. Roth, Nucl. Instr. Meth. B23 (1987) 518

6. L. E. Rehn, P. R. Okamato, D. J. Potter and H. Wiedersich, J. Nucl. Mater. 85 \& 86 (1979) 1139

7. A. R. Krauss and D. M. Gruen, J. Nucl. Mater. 85 \& 86 (1979) 1179

8. A. R. Krauss, D. M. Gruen, N. Q. Lam and A. B. DeWald, J. Nucl. Mater. 128 \& 129 (1984) 570

9. B. Baretzky, E. Taglauer, W. Möller and R. P. Schorn, I. Nucl. Mater. 162-164 (1989) 920

10. H. Barth, E. Muehling and W. Eckstein, Max Planck Inst. für Plasmaphysik Report IPP 9/58 (March 1986) 1-11

11. A. R. Krauss, D. M. Gruen, J. N. Brooks and A. B. DeWald, J. Vac. Sci. Technol. A4 (1986) 1227

12 A. B. DeWald, J. N. Brooks, A. R. Krauss, D. M. Gruen and M. G. Valentine, J. Nucl. Mater. 145-147 (1983) 373

13. A. R. Miedema, Z. Metallkunde 69 (1978) 455

14. 4. A. R. Krauss, D. M. Gruen, N. Q. J Jam, A. B. DeWald, M. G. Valentine, A. Sagara and K. Kamada, Scanning Microscopy 2 (1988) 1365

15. A. R. Krauss, O. Auciello, A. Uritani, M. Valentine, M. Mendelsohn and D. M. Gruen, Nucl. Instr. Meth B27 (1987) 209

16 A. R. Krauss, A. B. DeWald, D. M. Gruen and N. Q. Lam, Radiat. Effects 89 (1985) 129

17. C. J. Wen, B. A. Boukamp,R. A. Huggins and W. Weppner, J. Electrochem Soc. 126 (1979) 2258

18. A. B. DeWald et. al. pulse effects

19 A. R. Krauss, D. M. Gruen, M. H. Mendelsohn, R. rnnn, D. Goebel, Y. Hirooka and K. Leung, J. Nucl. Mater. 145 (1987) 401 
20. 9th PSI

21. G. Hanke \& K. Müller, Surface. Science 152/153 (1985) 902 


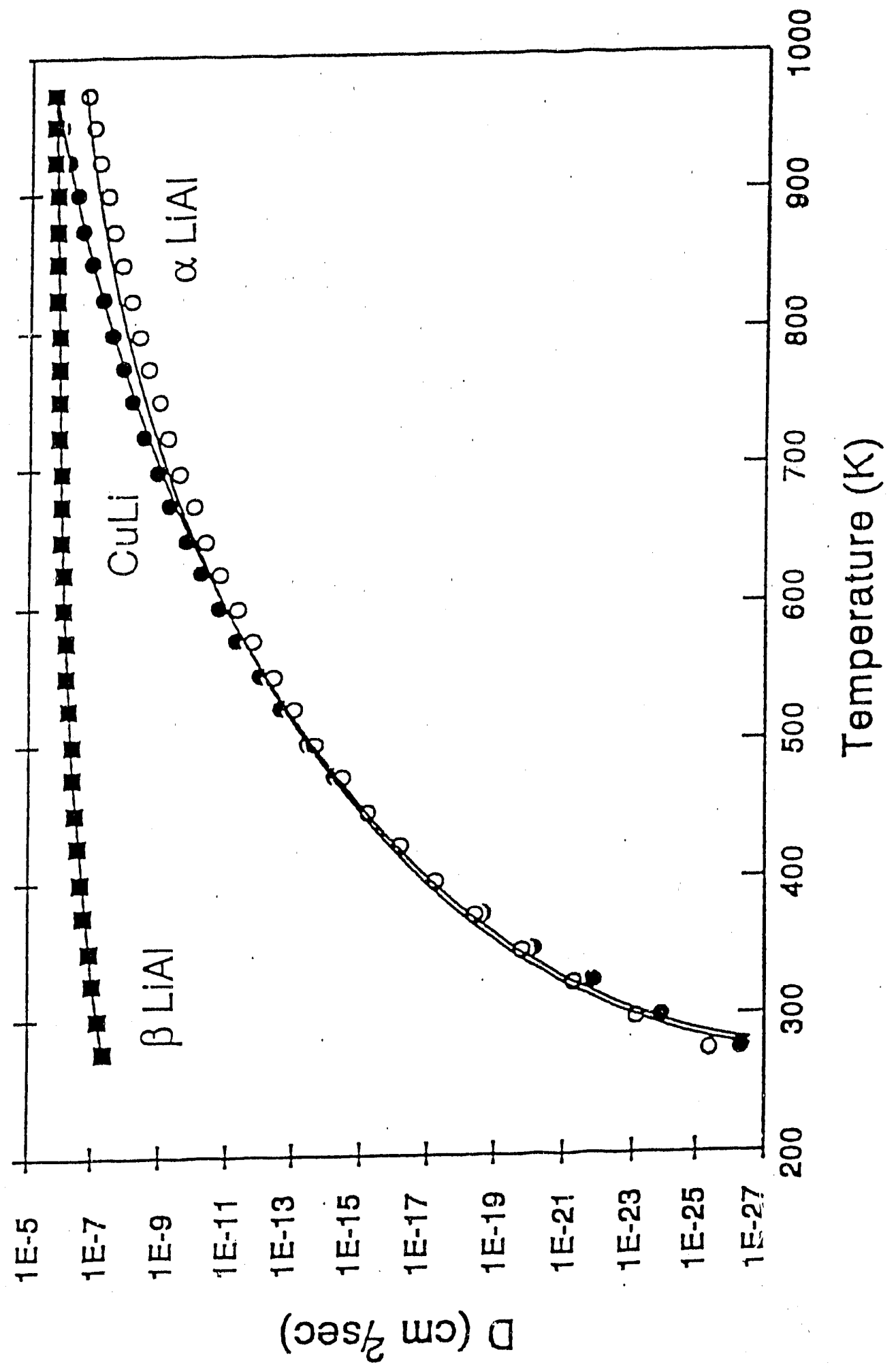




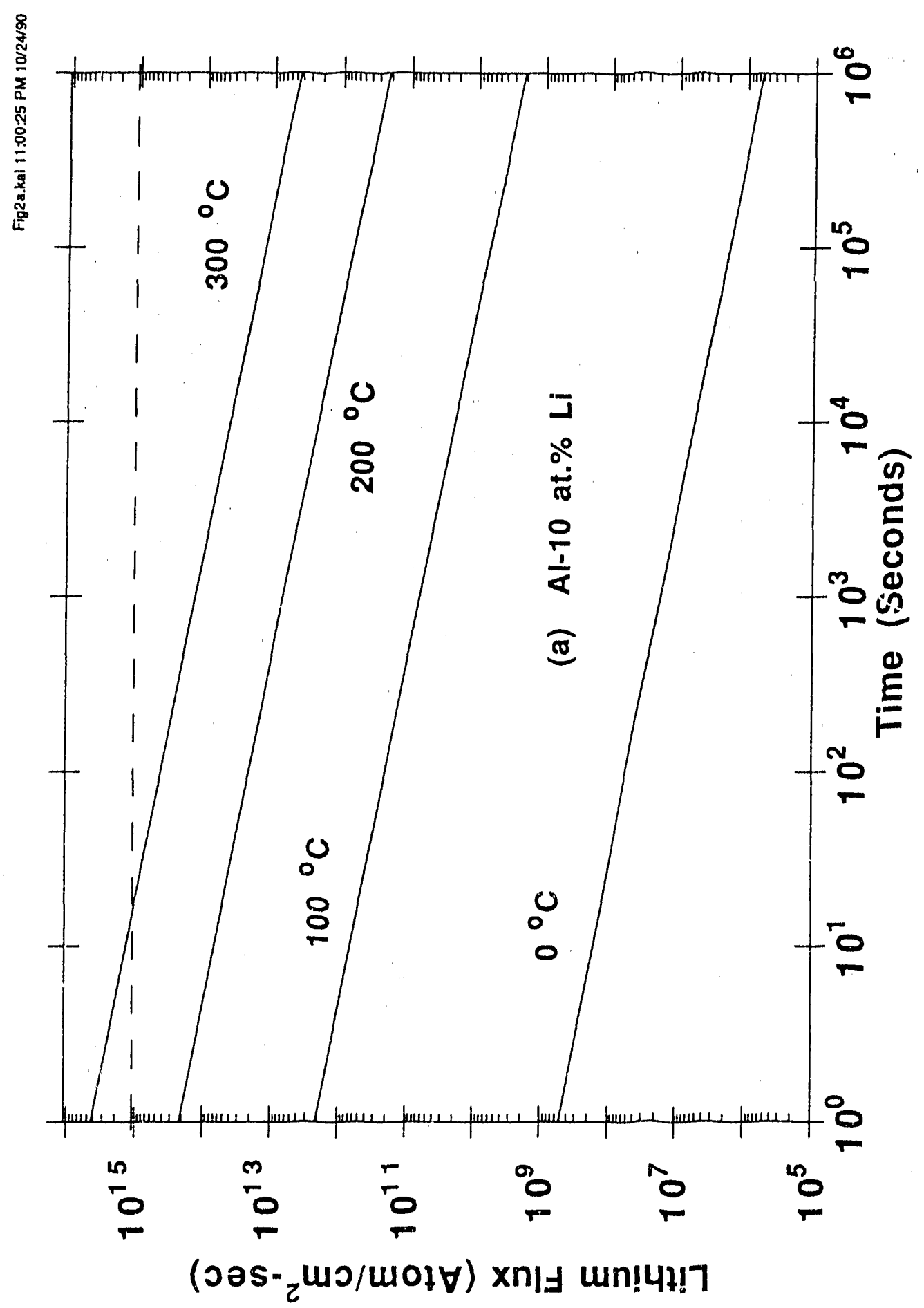




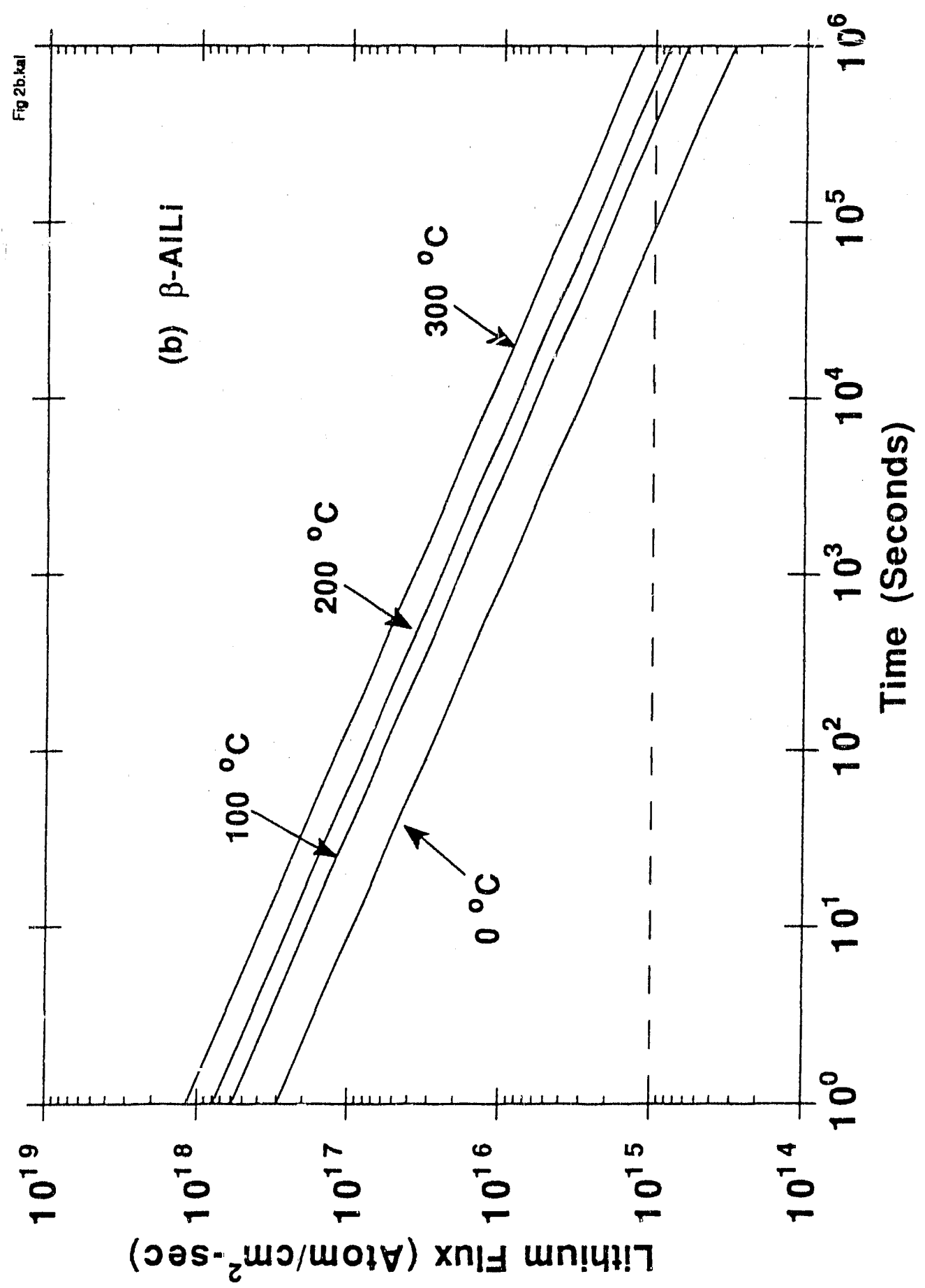



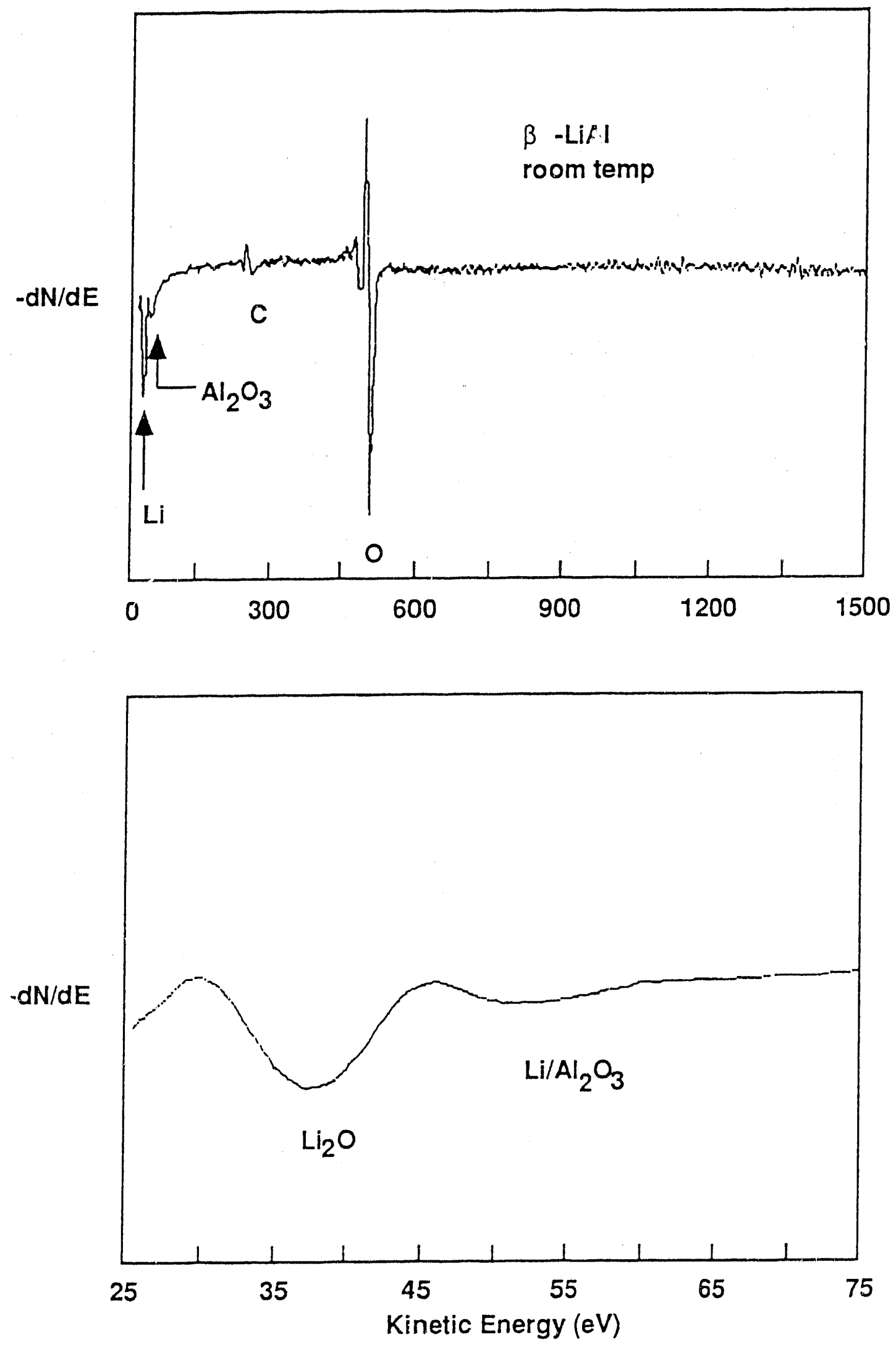

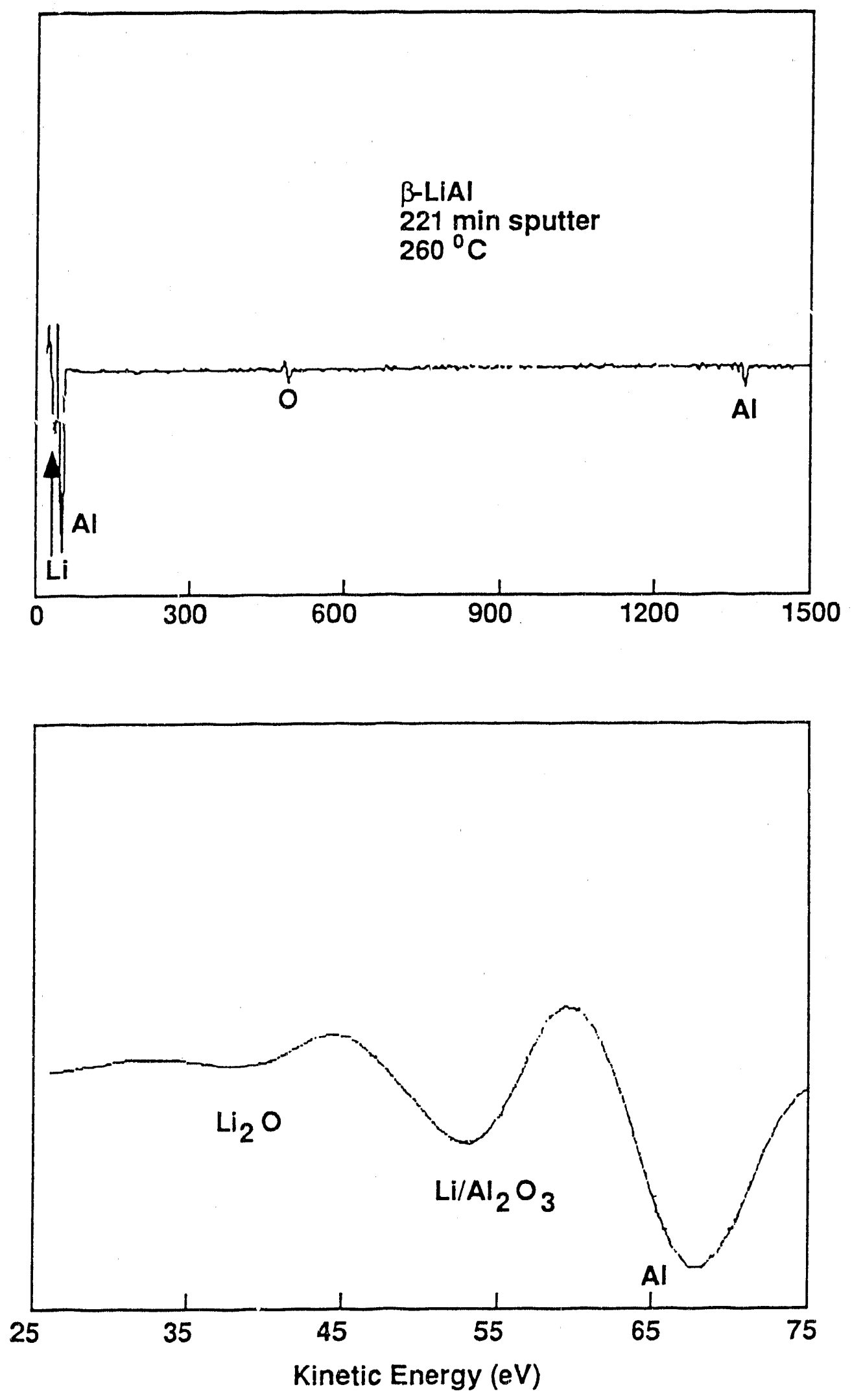


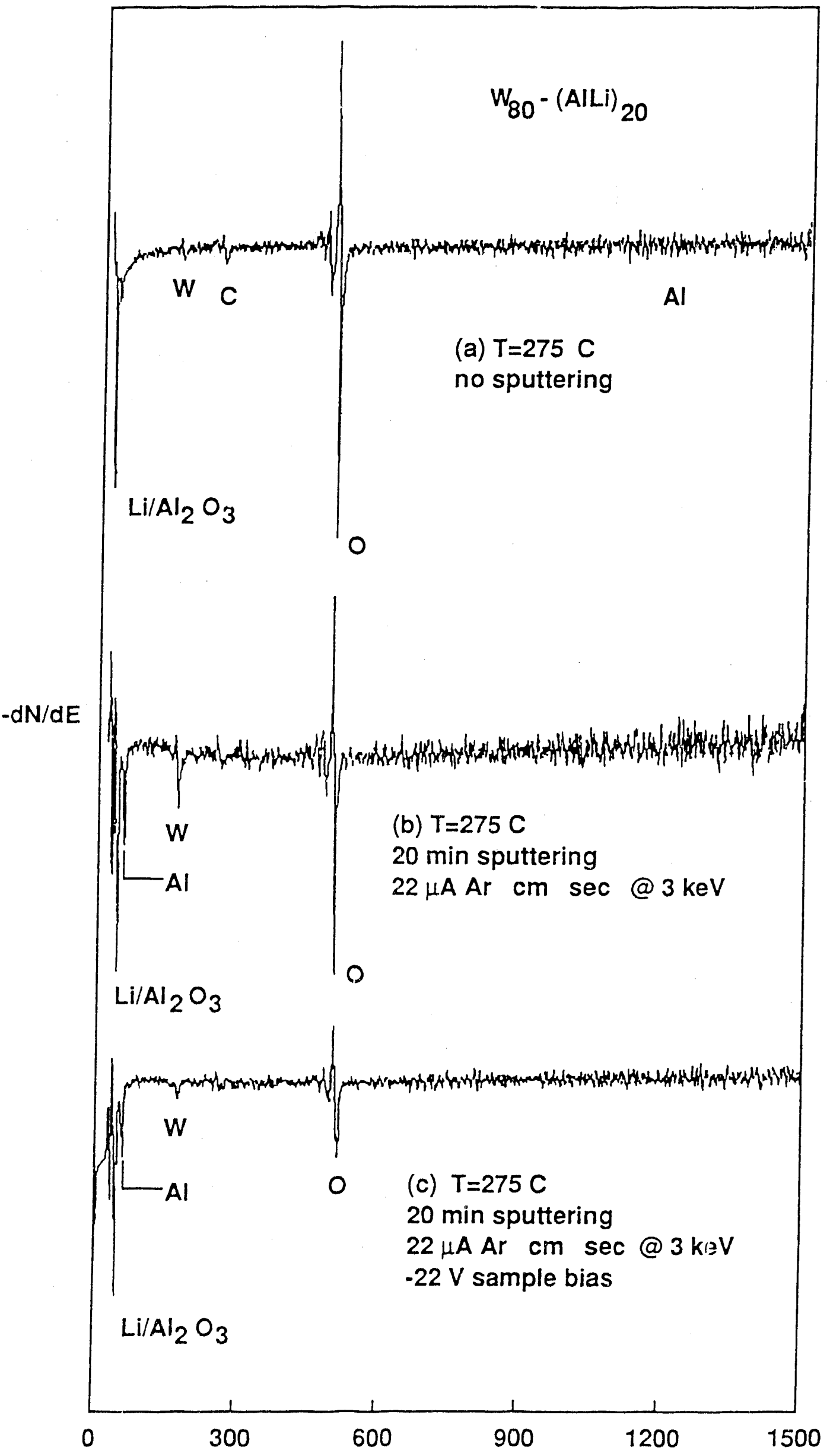




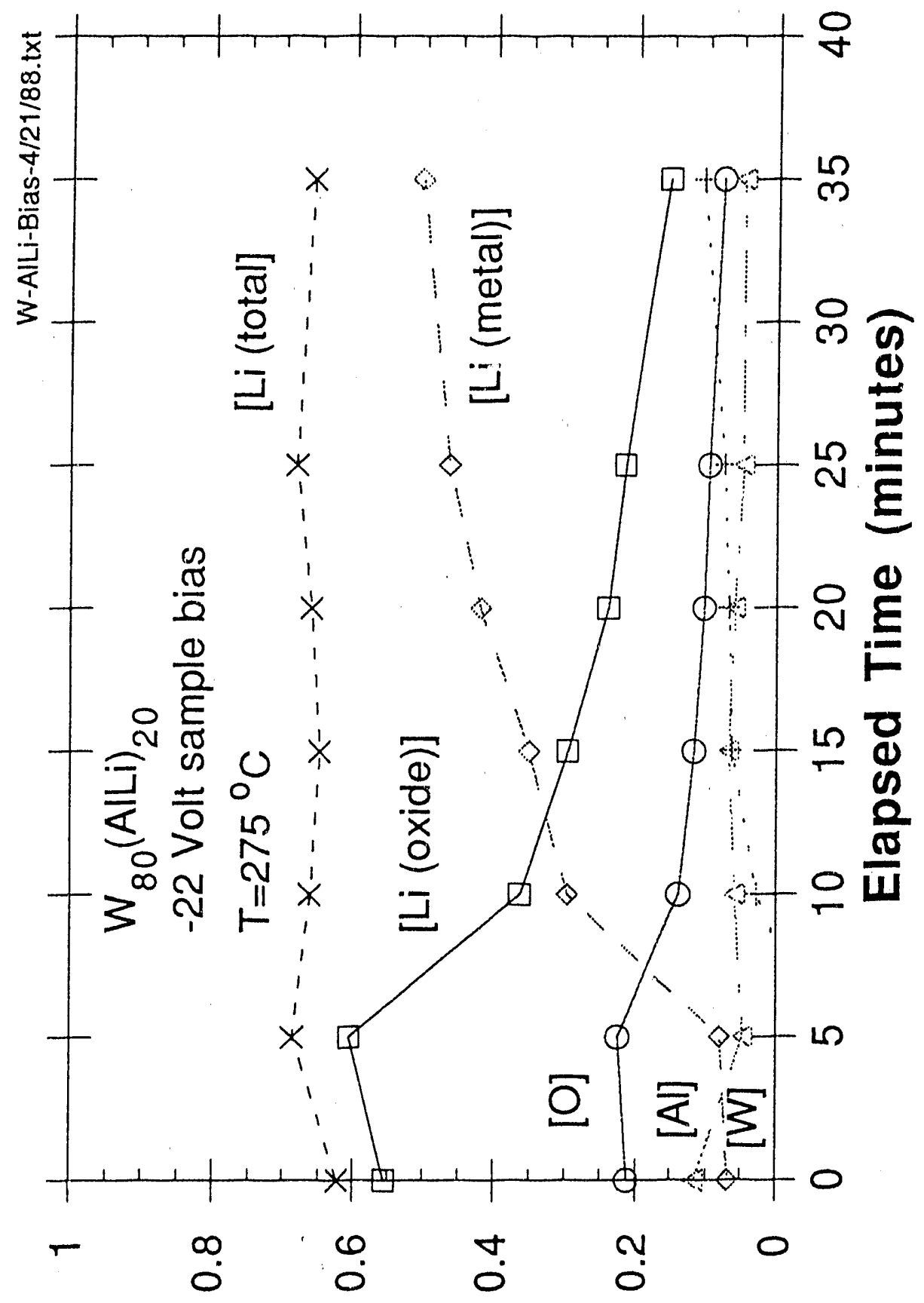

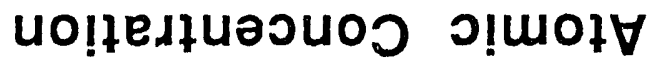




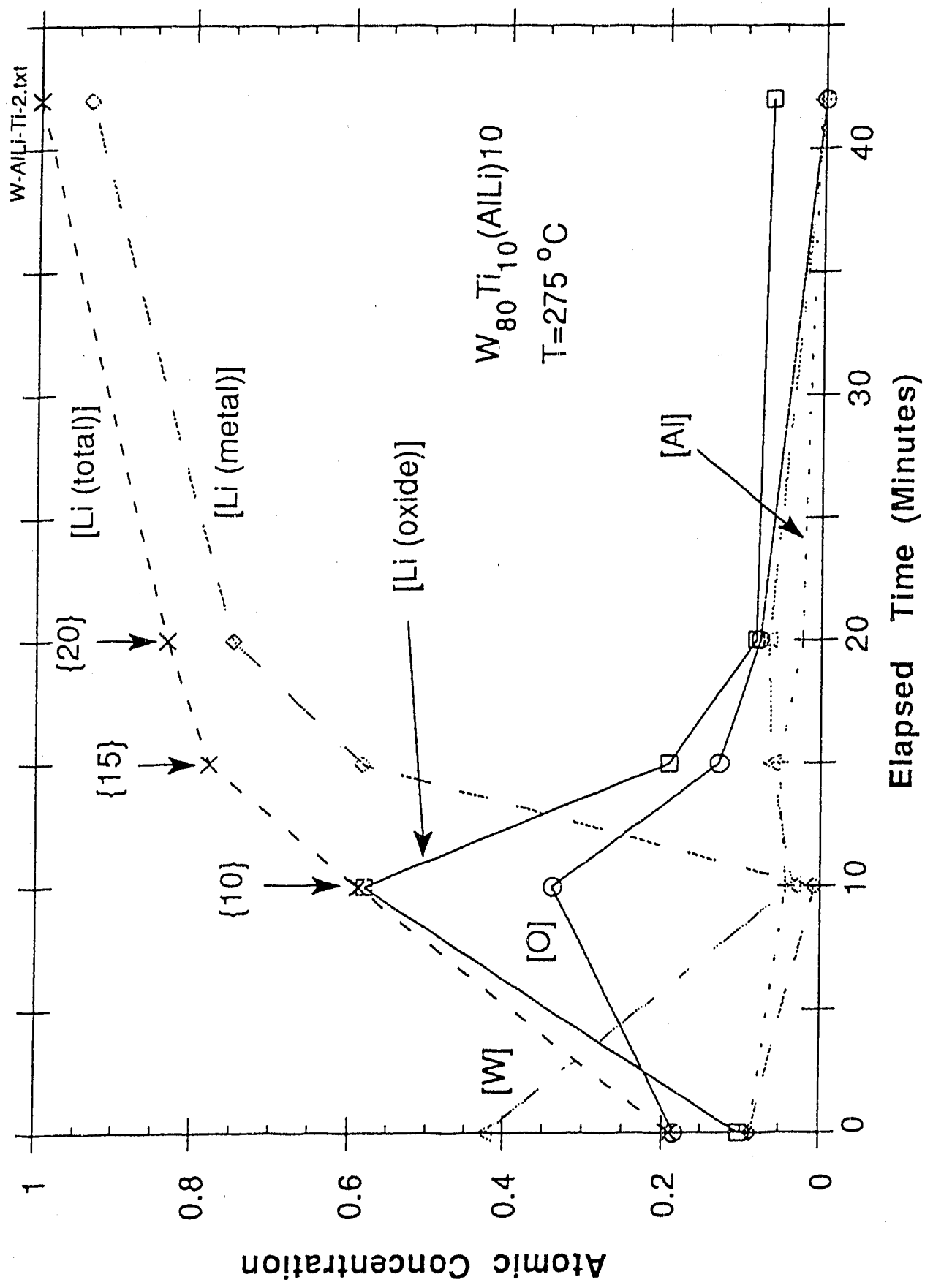



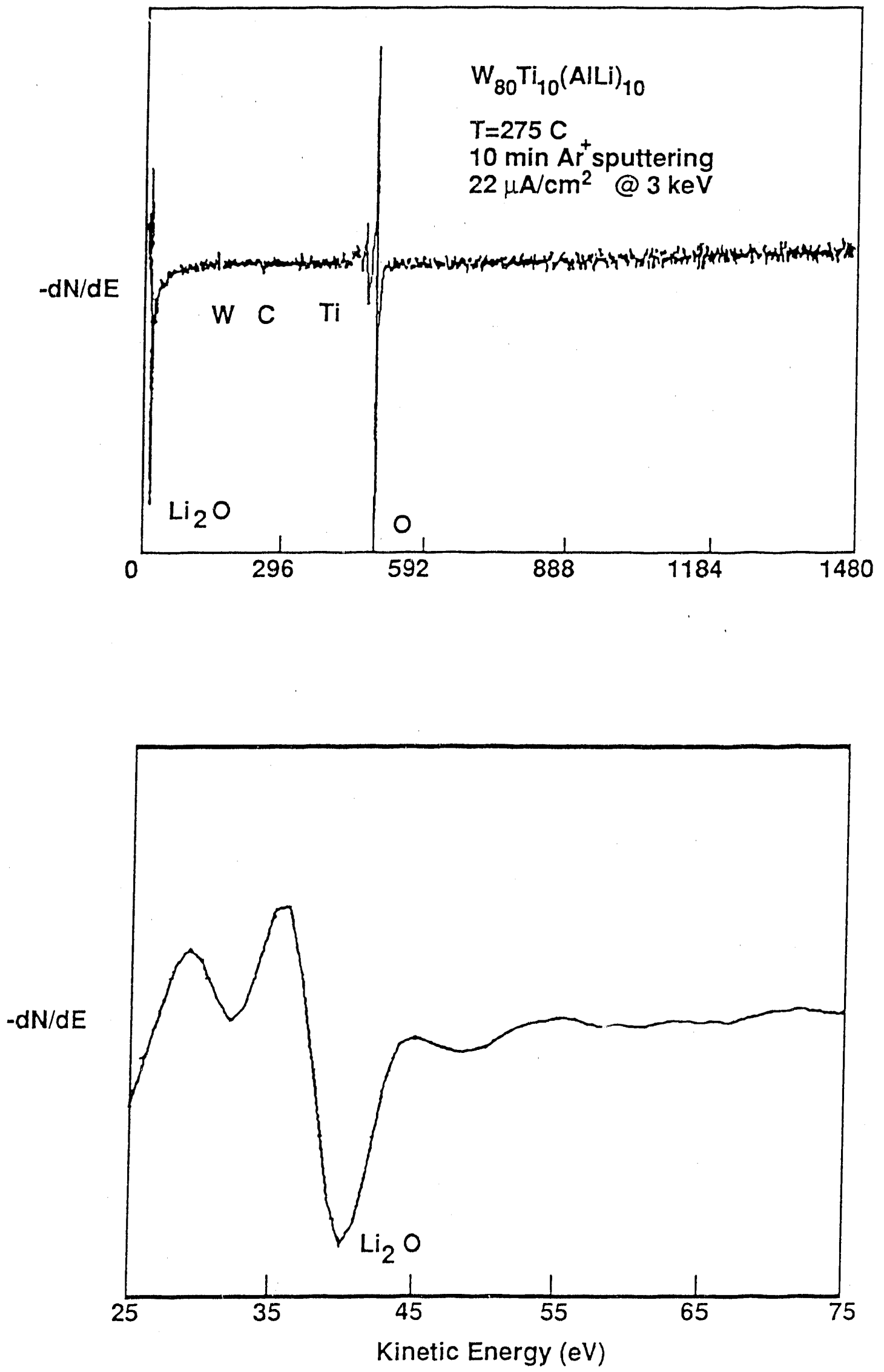

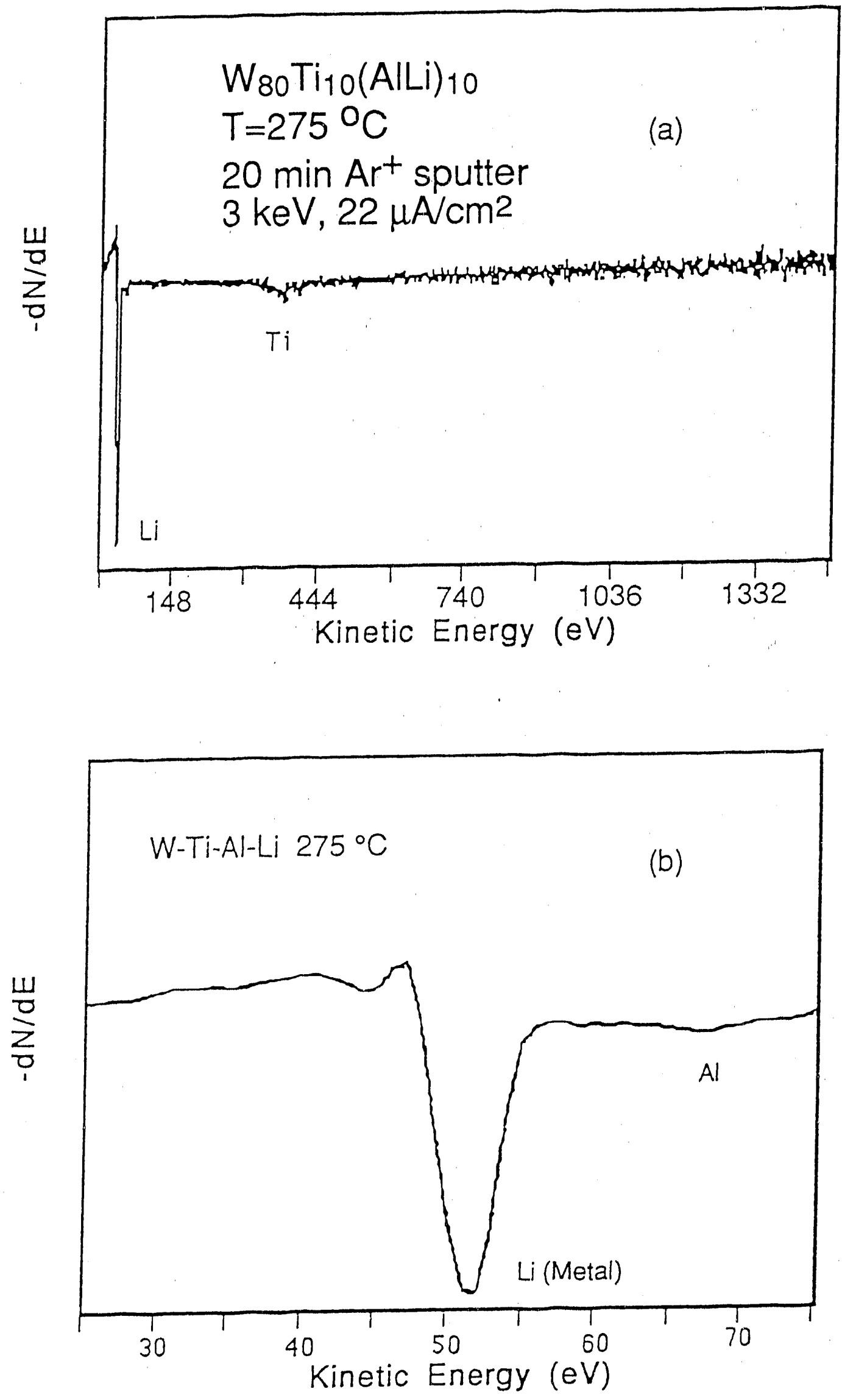

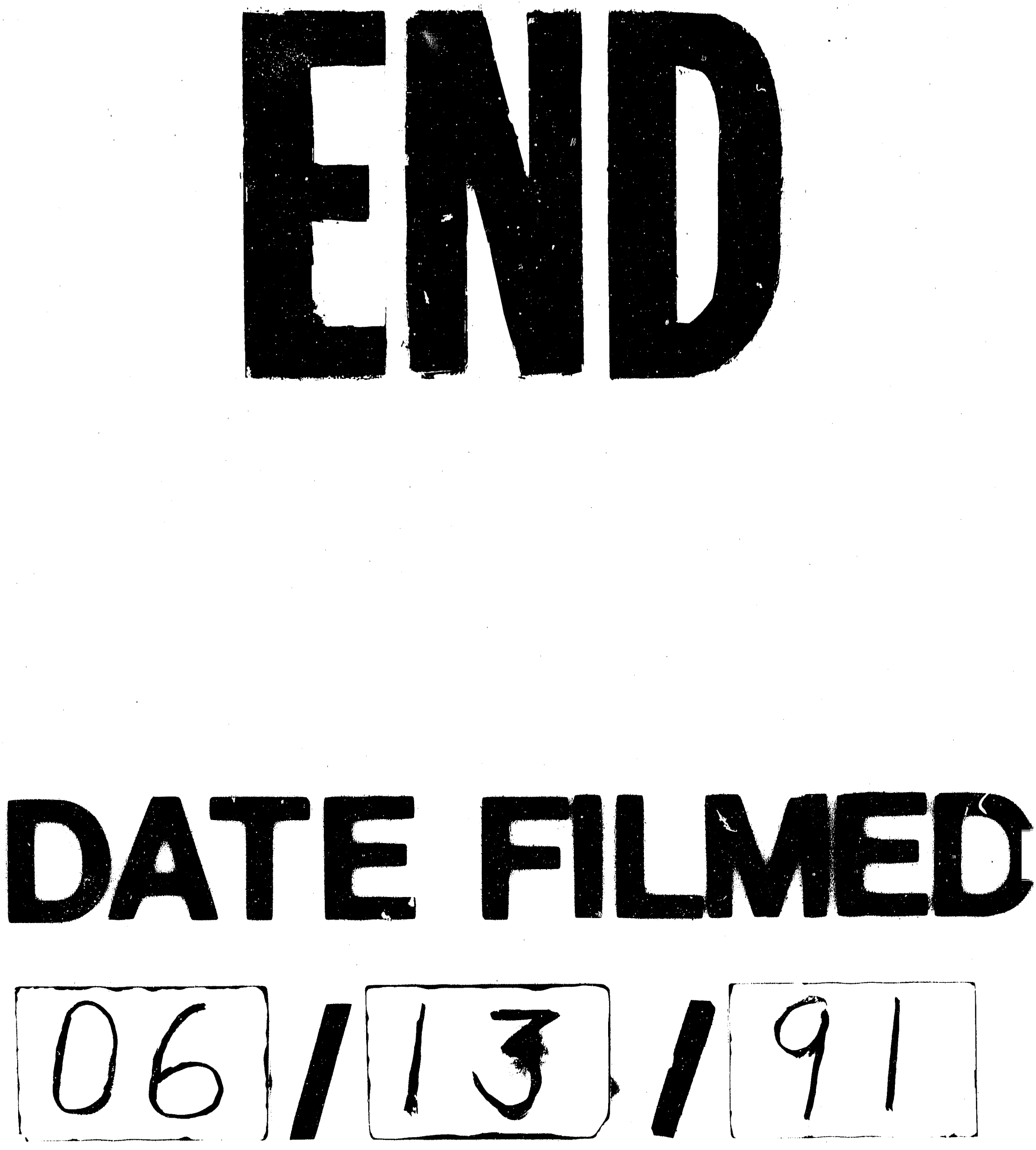
